\title{
Orientaciones deontológicas en el ejercicio de la profesión politológica
}

\section{Ethical guidelines in the exercise of the political science profession}

\author{
Bernabé Aldeguer-Cerdá \\ Profesor de la Universidad de Alicante, España \\ bernabe.aldeguer@ua.es \\ Recibido: 22/10/2014 - Aceptado: 16/03/2015
}

\section{Resumen}

El objetivo del presente artículo consiste en exponer, de manera sucinta y exploratoria, los principales componentes éticos y las orientaciones deontológicas básicas, a los cuales se enfrentan los/as politólogos/ as en el ejercicio de su profesión. Este escrito presenta los principales propósitos de la Ciencia Política y de la Administración, desde el punto de vista normativo y prescriptivo, más allá de la actividad descriptiva y explicativa de la realidad política. Se destacala importancia de los estándares deontológicos en el ejercicio de los objetivos evaluativos de la disciplina, así como la utilidad de la Ciencia Política y de la Administración en la generación de respuestas y propuestas a los problemas de las democracias contemporáneas.

\section{Palabras clave}

Deontología, Ciencia Política, disciplina, profesión.

\section{Abstract}

This article exposes, in a succinct and exploratory manner, the main ethical components and orientations that political scientists should take into consideration when exercising their profession. The article shows the core purposes of Political and Administration Science, from a normative and prescriptive point of view, beyond the descriptive and explicative approach to political facts and behaviors. It emphasizes the importance of ethical standards in the evaluative objectives of the discipline, as well as the usefulness of Political and Administration Science, generating solutions to the current social and political problems.

\section{Keywords}

Deontology, Political Science, discipline, profession.

1 Profesor de la Universidad de Alicante, España. Es licenciado en Ciencias Políticas y de la Administración por la Universidad Miguel Hernández (UMH). Premio Extraordinario de Licenciatura, Certificado de Excelencia Académica (Generalitat Valenciana) y Mención Especial del Ministerio de Educación (Gobierno de España). Máster en Gestión Pública y Liderazgo Político (Universidad de Alicante). Doctorando y miembro investigador del Observatorio Lucentino de Administración y Políticas Públicas Comparadas del Área de Ciencia Política y de la Administración de la Universidad de Alicante. Líneas de especialización: Ética Pública, Transparencia y Buen Gobierno; Gobierno y Gestión Local; y Élites parlamentarias desde la perspectiva de género. Correo electrónico bernabe.aldeguer@ua.es. 


\section{Introducción}

El objetivo del presente artículo consiste en exponer, de manera sucinta y exploratoria, los principales componentes éticos y las orientaciones deontológicas básicas, a los cuales se enfrentan los/as politólogos/as en el ejercicio de su profesión. Las líneas que siguen a continuación implican, según lo expuesto, en cierto modo, una aproximación al alcance de la teoría normativa o evaluativa en la Ciencia Política, y una reflexión sobre el papel de los/as politólogos/ as en sus atribuciones e indagaciones deontológicas en los ámbitos académico y profesional.

Resulta preciso comenzar destacando que cualquier investigación o proceso de reflexión y proposición, en el ámbito de la Ciencia Política, puede tener como objetivos, citando a Stoker (1997), los siguientes: 1) capturar y definir la esencia y las características de los actores, las instituciones, los procesos, los fenómenos y los comportamientos políticos; 2) la identificación de los factores que permiten explicar e interpretar los precitados aspectos de la realidad política; 3) la evaluación normativa y crítica de tales componentes de la realidad política (teorías evaluativas), así como, en última instancia; 4) una eventual proposición resolutiva de los objetivos desde la perspectiva del deber ser de las cosas del mundo (teorías normativas) (Stoker, 1997). Todo lo antedicho supone reconocer a la Ciencia Política no solo las atribuciones dirigidas a definir, describir o explicar los acontecimientos políticos, de acuerdo con Bartolini (1995), sino que, además de lo expuesto anteriormente, el ejercicio politológico puede implicar una valoración de tales acontecimientos relativos a la realidad política. Conforme a Landman (2012), la generación de conocimiento sobre los hechos, los actores y los procesos políticos puede suponer una reflexión sobre "cómo deben ser las cosas en la sociedad" (Landman, 2012), con la consiguiente posibilidad de generar propuestas y recomendaciones (Vallès, 2004).

\section{Teorías normativas}

Las teorías normativas quedan constituidas, pues, en el escenario de la Ciencia Política, por el conjunto de las investigaciones y las reflexiones que abordan las pautas básicas de acción sobre cómo deben ser las cosas en la dimensión política de la sociedad. Los estudios desarrollados en tales proposiciones académicas se erigen sobre argumentaciones de naturaleza teórica y deductiva, y se preocupan por cómo constituir y organizar las relaciones sociales, con la intención de procurar una mayor y mejor consecución y realización del bien común, por medio de "criterios de valor, juicios de valor y líneas de conducta para la acción" (Nohlen, 2012).

En suma, la Ciencia Política, más allá de describir la realidad política a través de los instrumentos y técnicas de investigación específicas por medio de las que opera, se proyecta también en el ámbito de la práctica política.

Como resulta obvio, desde la Ciencia Política se derivan innumerables posibilidades, en cuanto a la capacitación y la configuración de ciertos perfiles profesionales se refiere, en el ámbito de las administraciones públicas. Si bien, más allá de tal proyección de la disciplina, conviene destacar la propia capacidad de la Ciencia Política para ofrecer, a su vez, propuestas dirigidas al fortalecimiento de la democracia, el fomento de mejores y más sofisticados estándares de Ética Pública y, en general, de mejoramiento de las condiciones de vida de las sociedades, así como del rendimiento y la legitimidad de los sistemas políticos democráticos.

En el marco de las teorías normativas, centradas - como se ha visto- en el deber ser, y no tan solo en una primera constatación descriptiva de los procesos, los actores y las realidades políticas (el ser de la política y sus diversas manifestaciones), la Ciencia Política formaliza también su propósito para ofrecer proposiciones resolutivas ligadas a los principales componentes y manifestaciones de la política, en el marco de las llamadas teorías evaluativas (Stoker, 1997).

La condición o el componente normativo de la Ciencia Política radica, igualmente, en la identificación de una serie de conceptos, en tanto que objeto de estudio de la disciplina, tales como, entre otros, los términos y las nociones de utilidad, libertad, justicia, igualdad, lo correcto y lo justo, el contrato social, el papel de la religión en la política, la cohesión social, la extensión y los límites de las funciones del poder político y del Estado, o la legitimidad.

La Ciencia Política, según lo antes expuesto, trasciende, pues, a funciones de indudable utilidad social, tales como las de la interpretación crítica de la realidad política o el soporte de asesoría y consultoría, dirigido a actores políticos e instituciones para la adopción de decisiones colectivas, o la gestión de organizaciones y proyectos públicos ( $V$. gr., técnicos de participación ciudadana o gestores de cooperación internacional). 
Por tanto, y en última instancia, más allá de la descripción y el análisis explicativo, la vocación de toda investigación científica sobre la realidad política permite disponer de argumentos sólidos, rigurosos y exhaustivos que contribuyan al debate y la discusión doctrinal y teórica. En este sentido, en el relato cronológico sobre el proceso de institucionalización de la Ciencia Política, Batlle pone de manifiesto la importancia de una cierta tensión conceptual, metodológica y de enfoque o perspectiva, entre el conductismo y el normativismo, en el sentido de que

el conductismo no asumía una clara preocupación teórica o explicativa $y$, debido a una perspectiva excesivamente determinista, los conductistas no lograban dar cuenta de fenómenos contemporáneos como el feminismo o las luchas por la igualdad de derechos (Batlle, 2007).

De esta manera, la ética en el ejercicio profesional de la Ciencia Política, en sus diferentes perfiles y facetas, se patentiza y muestra su emergencia y utilidad por medio de diferentes principios, que tratan de identificar los principales dilemas a los que el politólogo se puede enfrentar, y el modo más adecuado de afrontarlos y resolverlos desde la responsabilidad que supone la actividad académica y profesional de la disciplina.

El politólogo debe, no obstante, tener en cuenta una serie de parámetros deontológicos claves, más allá de los cuales su reflexión propositiva puede suponer una extralimitación de su labor investigadora. Más allá de exhortaciones y recomendaciones cualificadas que el politólogo exponga, en el ejercicio de su labor investigadora, las disposiciones colectivas tienen reconocida la legitimación popular de las lógicas democráticas en cuanto a la adopción de decisiones.

De esta manera, se trata de identificar en qué medida el politólogo queda legitimado para ofrecer pautas de acción política a la ciudadanía, los profesionales públicos o los cargos electos. La evolución histórica de la Ciencia Política ha puesto también de manifiesto una clara vocación normativa basada - como ya se ha señalado- en la preocupación por el deber ser en las cuestiones resolutivas y decisivas de los procesos y los actores políticos. Esta perspectiva señalada se encuentra en la base de una cierta legitimación del politólogo en sus dimensiones consultiva, académica y eminentemente intelectual.
Más allá de la advertencia weberiana acerca de la neutralidad axiológica y la objetividad del politólogo, a la hora de exponer y evaluar los diferentes sistemas políticos, es preciso poner de relieve, además, la relación de la Ciencia Política con la democracia, en tanto que ciencia "de y para la democracia, como ciencia que enseñar la democracia, como ciencia en apoyo a la democracia" (Nohlen, 2012). Máxime ante la particular necesidad que la Ciencia Política tiene de desplegarse en un contexto ausente de intervenciones al libre pensamiento crítico (Cotarelo, 1994). No obstante, a pesar de tal función propositiva del politólogo, conviene no confundir su tarea con una legitimación para permitir que el politólogo, en su vertiente profesional específica de profesor, devenga en la figura del "demagogo" o "profeta" a la que alude Weber, y que vulnere la necesaria "probidad intelectual" del politólogo, máxime en su deber como profesor, en la enseñanza de la Ciencia Política (Weber, 2007).

Jerez (1999) sostendrá que la objetividad del/la politólogo/a "es perfectamente compatible con el compromiso ético y político respecto del argumento previamente elegido o con los resultados de la investigación, garantizando así la relevancia de la empresa científica" (Jerez, 1999).

La Ciencia Política y la Ciencia de la Administración, en tanto que ciencias sociales que pudieran quedar excesivamente marcadas por un componente acentuadamente positivista, resultarían éticamente neutras, en términos de Strauss (1970). Tal circunstancia supondría, siguiendo a Llano (1999), una suerte de nihilismo que la invalidaría absolutamente.

Ciertamente, de acuerdo con Camps (1999), cabe reflexionar sobre: "¿Cómo separar el conocimiento del mundo del propósito de transformarlo en La República de Platón, en la Ética de Spinoza o en La Gaya?" (Camps, 1999). De este modo, el debate sobre el componente normativo y la función programática de la Ciencia Política y la Ciencia de la Administración remite a la diferenciación entre: 1) la mera "constatación de los hechos", de una parte; y 2) el estudio basado en el "valor de la cultura y de sus contenidos concretos $y$, dentro de esta, cuál tiene que ser el comportamiento del hombre en la comunidad cultural y en sus asociaciones políticas" (Weber, 2007).

En última instancia, de acuerdo con Lipset (1959): "Ayudar a las acciones de los hombres para fortalecer la democracia fue en cierta manera lo que se propuso Tocqueville al estudiar 
el funcionamiento de la democracia estadounidense, y sigue siendo quizá la tarea intelectual sustantiva más importante a que aún pueden consagrarse los estudiosos de la política" (Lipset, 1959).

Los códigos deontológicos implican el reconocimiento de una serie de principios éticos y de conducta, por medio de los que determinar las responsabilidades del politólogo en el desempeño de los diferentes perfiles profesionales, fundamentalmente como investigadores, profesoresdocentes, políticos en activo, empleados públicos o como autores intelectuales de obras académicas o de otra naturaleza (ensayos, informes...). A través de tales códigos, se abordan áreas y ámbitos tales como: 1) preservar, observar y hacer uso de las técnicas e instrumentos de investigación más adecuadas a los propósitos de investigación; 2) el rechazo al intrusismo profesional; 3 ) el mantenimiento de la reputación social y científica de la disciplina y de la profesión; así como 4) los términos y condiciones más apropiados para garantizar la confidencialidad y el consentimiento informado en la obtención, el archivo, el tratamiento y la publicación de la identidad de los sujetos de una muestra u objeto de investigación.

\section{Conclusiones}

Conviene destacar que la plena vigencia y efectividad de la ética, en el ámbito del ejercicio profesional de la Ciencia Política, no solo depende de la inicial aprobación de un determinado código deontológico, sino que, en última instancia, viene dada por un conjunto de acuerdos institucionales que permitan su seguimiento y efectiva implantación. Los Comités de Ética permiten identificar y actualizar los catálogos deontológicos, así como garantizar la observancia de estos en la práctica de la profesión, mediante la interpretación de eventuales conflictos deontológicos y el establecimiento, en su caso, de las sanciones que correspondan por un obrar negligente y contrario a la probidad de la profesión.

Finalmente, conviene contextualizar las reflexiones realizadas más arriba, en el inexcusable compromiso de los intelectuales, los académicos y los profesionales de la Ciencia Política y de la Administración, para con las sociedades en las que desarrollan sus actividades como expertos, pero también como ciudadanos. Resultaría ocioso y reiterativo enumerar e incidir en la complejidad de los escenarios contemporáneos, así como en las problemáticas estructurales de la actualidad; a saber: el cambio climático, el urbanismo, las migraciones, el envejecimiento poblacional, la pobreza y las crisis humanitarias. A ello cabría añadir el surgimiento y el ascenso de los nuevos movimientos sociales de vocación democrática, un contexto que convive, no obstante, con la consolidación de un conjunto de actitudes de insatisfacción con respecto al funcionamiento de los sistemas democráticos, todo lo cual incide en la necesidad de fortalecer las prácticas esenciales de la democracia. Ante tal contexto, la Ciencia Política y de la Administración permite capacitar y formar a los cuadros políticos, profesionales y sociales, así como a la ciudadanía en general, con el objetivo de afirmar y vigorizar los principios y los valores eminentemente democráticos, involucrando desde los profesionales de las administraciones públicas hasta a los ciudadanos más desfavorecidos; en este caso por medio de la cohesión social como premisa para la constitución del cuerpo político, pasando por las élites políticas, los agentes sociales y los diferentes grupos y colectivos en que se articulan las poliarquías. En última instancia, el compromiso de la disciplina, sujeta a unos parámetros y estándares claros y rigurosos, de ética y deontología profesional permitirá afianzar el natural vínculo entre la Ciencia Política y de la Administración con la democracia.

\section{Referencias}

Aldeguer Cerdá, B. (2013). “Ética Pública y Gobierno Local en un contexto de crisis económica". Barataria. Revista Castellano-Manchega de Ciencias Sociales, n. ${ }^{\circ} 15$. ISSN: 1575-0825.

Aldeguer Cerdá, B. (2011). “La Ética Pública en la configuración del Nuevo Servicio Público". Más Poder Local. Número 7 (Octubre 2011): “Gobernabilidad, retos y respuestas para las democracias. Departamento de Comunicación Política e Institucional de la Fundación Ortega-Marañón". (Madrid). ISSN: 2172-0223.

Batlle, A. (2007). "Introducción", en Batlle, A. Diez Textos Básicos de Ciencia Política. Barcelona: Ariel.

Camps, V. (ed.). 1999. Historia de la Ética. Madrid: Crítica.

Cotarelo, R. (1994). “La Ciencia Política en España”, en Cotarelo, R. (ed.). Las Ciencias Sociales en España. Historia inmediata, crítica y perspectivas. Madrid: Ed. Complutense y Caja de Ahorros y Monte de Piedad de Madrid.

Jerez, M. (1999). Ciencia Política, un balance de fin de siglo. Madrid:Centro de Estudios Políticos y Constitucionales (CEPC). 
Landman, T. (2012). Política comparada. Una introducción a su objeto y métodos de investigación. Madrid: Alianza Editorial.

Lipset, S.M. (1959). "Some Social Requisites of Democracy: Economic Development and Political Legitimacy.". American Political Science Review 53 (March): 69-105.

Llano, A. (1999). Humanismo Cívico. Madrid: Ariel.

Nohlen, D. (2012). ¿Cómo estudiar Ciencia Política? Una introducción de trece lecciones. Madrid: Marcial Pons.

Stoker, G. (1997). "Introducción", en Marsh, D. y Stoker,
G. Teoría y métodos de la ciencia política. Madrid: Alianza (Universidad Textos).

Strauss, A. (1970) "Descubriendo nuevas teorías de teorías previas", en Shibutani (comp), Naturaleza humana y comportamiento colectivo. Ensayos en honor a helbert blumer, Nueva Jersey: Prentice-Hall.

Vallès, J.M. (2004). Ciencia política. Una introducción. Barcelona: Ariel (Ciencia Política).

Weber, M. (2007). El político y el científico. Madrid: Alianza Editorial (Ciencia Política). 